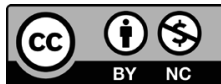

\title{
SOCIEDADE DA INFORMAÇÃO E DIREITO À PRIVACIDADE NO MARCO CIVIL DA INTERNET: FUNDAMENTAÇÃO FILOSÓFICA DO ESTADO DE DIREITO EM JOHN FINNIS
}

INFORMATION SOCIETY AND RIGHT TO PRIVACY IN THE INTERNET LAW: PHILOSOPHICAL FOUNDATIONS OF THE RULE OF LAW IN JOHN FINNIS

Victor Sales Pinheiro

Alexandre Pereira Bonna

\section{RESUMO}

Este Artigo analisa o risco de relativização dos direitos fundamentais ao devido processo legal e à privacidade pelos Projetos de Lei 215/2015, 1.547/2015 e 1.589/2015, que visam a alterar a Lei 12.965/2014. Para tanto, apresenta a complexidade da sociedade da informação e os seus riscos ao direito à privacidade. Em seguida, defende a inconstitucionalidade desses Projetos, que permitiriam a quebra de sigilo de dados, em ambiente virtual, por autoridade policial ou do Ministério Público, sem a autorização judicial. Por fim, fundamenta filosoficamente o direito à privacidade e o Estado de Direito a partir da teoria da lei natural de John Finnis.

Palavras-Chave: Sociedade da informação. Direito à privacidade. Estado de Direito. 


\section{ABSTRACT}

This Article analyzes the risk of relativization of fundamental rights to due process and privacy by the Project of Laws 215/2015, 1.547/2015 and $1.589 / 2015$, which aim to amend the Law $12.965 / 2014$. It presents the complexity of the information society and its risks to the right to privacy. Then, it defends the unconstitutionality of these Projects, which would allow the breach of confidentiality of data, in virtual environment, by police authority or by the Public Prosecution Service, without the judicial authorization. Finally, it grounds philosophically the privacy right and rule of law in the natural law theory of John Finnis.

Keywords: Information Society. Right to privacy. Rule of law.

\section{INTRODUÇÃO}

O século XXI é marcado pela revolução tecnológica em todas as esferas da vida. Não há praticamente nenhum aspecto de nossa existência individual, social, comercial e política que não esteja pautado na tecnologia digital da Internet, que facilita imensamente a captação de dados, a organização de informações e a comunicação entre as pessoas e entidades públicas e privadas.

As mudanças que essa revolução tecnológica causam são tão radicais e imediatas que dificilmente o Direito consegue compreendêlas e acompanhá-las. Antes da promulgação da Lei 12.965/2014, havia grande insegurança jurídica sobre o direito do mundo eletrônico, com o extensivo apelo a princípios constitucionais, analogias, doutrinas e jurisprudência, muitas vezes desconexos entre si.

No ordenamento jurídico nacional, a primeira normatização sistemática do ciberespaço se deu com essa lei, chamada Marco Civil da Internet, pautado na vocação constitucional de proteger os direitos fundamentais do nosso Estado de Direito, sobretudo o direito à privacidade, tão vulnerável na rede mundial de computadores, seja pela sua invasão privada - como pela divulgação de dados cadastrais com fins comerciais e políticos -, seja pela intromissão pelo próprio Estado - como em sede de investigação policial ou judicial. 
Porém, conforme alertam Pinto e Guimarães (2016), essa vocação garantista do Marco Civil encontra-se atualmente ameaçada pelos projetos de Lei 215/2015, 1.547/2015 e 1.589/2015, pois eles pretendem alterar dispositivos centrais do Marco Civil, fragilizando o direito fundamental à privacidade e a garantia do devido processo legal, tão centrais ao Estado Constitucional de Direito.

Neste Artigo, portanto, após traçarmos os riscos da sociedade da informação, na primeira seção, analisamos essas ameaças aos direitos à privacidade e ao devido processo legal do ponto de vista do direito constitucional, na segunda seção. Por fim, na terceira seção, refletimos sobre os fundamentos filosóficos do Estado de Direito, a fim de articular a sua autoridade formal (processual) à normatividade substancial (ética) das garantais fundamentais da pessoa humana, a partir da teoria da lei natural de John Finnis e Robert George.

\section{OS RISCOS DO DIREITO À PRIVACIDADE NA SOCIEDADE DA INFORMAÇÃO}

Há décadas atrás, a informação era de difícil transmissão, armazenamento e produção; mas, hoje, ela é fomentada pelos avanços tecnológicos, ocupando papel de destaque na sociedade contemporânea, alcançando primazia mesmo sobre os bens materiais, cujo valor passa a ser condicionado à sua relação com a informação e conhecimento agregados.

Neste trabalho, consideramos as ameaças ao direito à privacidade diante dos desafios específicos da sociedade da informação, que pode ser definida como uma nova forma de organização social que recorre ao intensivo uso da tecnologia da informação para coleta, produção, processamento, transmissão e armazenamento de informações, como no uso das tecnologias de computação e telecomunicações. Por sua vez, informação consiste em um dado ou conjunto de dados em qualquer suporte capaz de produzir conhecimento, podendo ser uma imagem, som ou documento (VIEIRA, 2007, p. 156).

Salienta-se que, no mundo contemporâneo, a informação é o princípio ativo da sociedade no sentido de que o trabalho, o lazer, a saúde, a educação, 
a política e economia dependem de informação, motivo pelo qual tem se potencializado a tecnologia na facilitação da sua coleta, produção, transmissão e armazenamento, na esfera da chamada revolução da tecnologia da informação (VIEIRA, 2007, p. 157).

Tal sociedade da informação compreende o uso de redes sociais, como o Facebook, Instagram e Twitter, assim como aplicativos, como o Whatsapp e Tinder, e lojas de compras online como OLX e Mercado Livre. Porém, em um contexto mais amplo, envolve também os cadastros de consumidores em lojas e hospitais, os dados sobre processos judiciais, débitos fiscais, assim como bancos de dados privados de empregadores e públicos da administração do governo. É difícil imaginar qualquer aspecto da sociedade atual que não esteja ancorado numa plataforma digital, que contém praticamente todas as informações constitutivas das relações sociais, econômicas e jurídicas em geral.

Assim, boa parte da informação que livremente expomos da nossa personalidade fica retida em plataformas digitais de comunicação digital à nossa revelia, sem que possamos controlar a reprodução e o acesso posterior a elas. Nesse esmaecimento das fronteiras entre o público e o privado, perdemos nossa autodeterminação informativa, o direito ao esquecimento, a possibilidade de resguardarmos nossa privacidade (OLIVEIRA; BARROS; PEREIRA, 2017). Com efeito, o incremento tecnológico da informação possibilitou uma abrangência maior na busca, coleta, armazenamento e disseminação dos dados pessoais, de modo que todos adquirimos uma personalidade digital que pode ser explorada sem o devido controle de privacidade (ROCHA; CUNHA; OLIVEIRA, 2017).

Assim, percebem-se vários pontos de tensão entre a sociedade da informação e o direito à privacidades, como 1. o abuso dos dados pessoais fornecidos na internet; 2 . a dependência e vulnerabilidade da plataforma digital; e 3. a consequente normalização e inevitabilidade do risco.

0 primeiro ponto de tensão identificado concerne às novas tecnologias de apreensão de dados pessoais que podem gerar efeitos negativos na vida das pessoas, ao comercializar informações pessoais como senhas, paradeiros, costumes sociais e endereço, transformando a privacidade em mercadorias. Trata-se de tecnologias que registram as buscas que fazemos na Internet para vender a publicitários. Isso pode ofender a 
honra (ao expor a intimidade moral, sexual, profissional e religiosa), pode expor informações que o sujeito gostaria de reservar apenas para si ou seus familiares (como doenças, deformidades, conta bancária, débitos fiscais ou em lojas), ou ainda pode expor os indivíduos a ceder pressões externas que influenciam suas escolhas (HOVEN, 2008).

É pertinente a essa discussão da privacidade na Internet o uso de cookies, que são dados armazenados no computador do usuário sobre quais sites ele buscou. Em tese, esse registro do lastro de navegação do internauta serviria para a melhoria dos sites, contudo alguns cookies podem servir para que o comércio conheça os gostos e preferências do usuário para enviar anúncios de um produto que o usuário tenha visualizado recentemente. A "memória” da Internet, assim como a tecnologia de associação entre comportamos análogos é potencialmente infinita, tornando-se um instrumento poderoso para o rastreamento e análise do comportamento social para fins comerciais e propagandísticos em geral, inclusive no campo político.

Portanto, na atual conjuntura, no momento em que buscam sites para pesquisas em geral, informações, compras, e relacionamentos sociais, os usuários se cadastram, fornecendo inocentemente suas informações pessoais como nome completo, $\mathrm{RG}, \mathrm{CPF}$, endereço, número de telefone, na medida em que as redes sociais, aplicativos e sites de compra desejam mais e mais dados de modo a aumentar o valor do site, alegando que o seu perfil está incompleto, já que informação é uma das maiores riquezas da sociedade de capital informacional.

Além do computador, verifica-se uma série de outros dispositivos, como telefones, outros equipamentos móveis como o GPS, que servem para coletar e enviar mais dados, inclusive de localização, os quais geram o risco de sujeitar a pessoa a perseguições e roubos, caso essas informações sejam vazadas.

Outro ponto marcante da sociedade da informação que tenciona a privacidade é que, quanto mais o setor público e o setor privado se tornam dependentes das tecnologias da informação, mais sujeitos estarão a ataques de pessoas mal-intencionadas. Nesse afã de supervalorizar a tecnologia da informação, "quanto mais um governo e uma sociedade dependem de sua rede de comunicação, maior sua exposição a ataques 
de hackers, crackers e de organizações criminosas, crescendo crimes cometidos em meio eletrônico" (VIEIRA, 2007, p. 162-163). Nesse sentido, basta imaginar que um simples conserto de um computador ou celular em uma loja especializada pode permitir a intromissão em todos os vídeos, fotos e conversas daquela pessoa. Da mesma forma, caso uma rede social ou um e-mail fique disponível em um espaço digital a que outras pessoas tenham acesso, facilmente será possível acessar todas as conversas com clientes e diálogos privados, caracterizando uma maior vulnerabilidade de intromissão dada a maior dependência com tecnologias.

De fato, no ciberespaço, a privacidade deixa de ser um direito e passa a ser uma commodity, já que "a informática possibilita não só acumular informações em quantidade ilimitada sobre a vida de cada indivíduo (suas condições físicas, mentais, econômicas ou suas opiniões religiosas e políticas), como também confrontar, agregar, rejeitar e comunicar as informações obtidas." (TEIXEIRA; SABO; SABO, 2017, p. 620)

Outra tensão diz respeito ao constante e aparentemente insuperável risco de invasão e intromissão na sociedade da informação. Com efeito, o compartilhamento online de informações pessoais dificilmente é considerado seguro, mesmo que a tecnologia da informação o anuncie e mesmo que haja vultuoso investimento em criptografia digital. É como se houvesse uma propensão tecnológica à divulgação e ao acesso, em detrimento da proteção e privacidade.

Por isso, as decisões e atividades do presente são marcadas pela dependência a danos futuros, a partir de uma sensação social generalizada de inevitabilidade do risco. Em face de o saber estar ligado a avaliações passadas de riscos já conhecidos (visão retrospectiva) e de sua incapacidade de racionalizar eventos futuros de riscos desconhecidos (visão prospectiva) mas altamente impactantes, constata-se a perda de confiança nos centros de decisão no tocante à garantia de segurança, de modo que a sociedade convive com uma normalização do risco, inclusive no âmbito das tecnologias da informação. Esse fato social atenta diretamente contra o ideal de segurança jurídica intentado pelo Estado de Direito.

Diante desse quadro sociológico, percebe-se que vivemos um momentos de grande instabilidade e fluidez, assim como de construção de novas formas de comunicação, pensamento e vida. Essa crise social 
da modernidade avançada pode ser motivo de pessimismo, incerteza e mesmo desespero. Porém, neste momento histórico, não se pode renunciar a grandes conquistas sociais, jurídicas e políticas, como o direito à privacidade, mesmo que a tecnologia da informação pareça neutralizá-lo. Como salienta o sociólogo Bauman (2013, p. 113): “Perdemos a coragem, energia e sobretudo disposição de persistir na defesa desses direitos, esses tijolos insubstituíveis na construção da autonomia individual. (...) A área da privacidade está se transformando num local de encarceramento."

Nesse contexto, a privacidade seria uma das últimas fortalezas sitiadas pela sociedade, economia e política moderna, cuja perda registra a falência do Estado de Direito, como garantidor da dignidade da pessoa humana pelo exercício de direitos fundamentais.

\section{OS DIREITOS FUNDAMENTAIS AO DEVIDO PROCESSO LEGAL E À PRIVACIDADE NO MARCO CIVIL DA INTERNET}

Como vimos na seção anterior, nossa sociedade da informação se caracteriza pela onipresença da Internet, instaurando uma realidade virtual que não pode ficar imune à normatização do Direito, em nome da segurança jurídica proporcionada pelo princípio da legalidade, no contexto do Estado de Direito. Os fundamentos filosóficos da autoridade e da normatividade desse Estado Constitucional serão analisados na próxima seção. Nesta, abordamos a insurgência no Marco Civil, instrumento regulatório primordial da Internet no Brasil no que concerne à proteção de direitos e garantis fundamentais, hoje ameaçadas pelos Projetos Legislativos já mencionados.

O Marco Civil da Internet (Lei 12.965/2014) foi pautado, dentre outras contribuições da intensa mobilização da sociedade civil em geral, pelo conjunto de recomendações constantes da Resolução CGI. br/RES/2009/003/P, do Comitê Gestor da Internet no Brasil - CGI.br, órgão da Presidência da República. Dos dez princípios para a governança e uso da Internet formulados nesse importante Documento, três merecem destaque para a argumentação deste Artigo: 


\section{Liberdade, privacidade e direitos humanos}

0 uso da Internet deve guiar-se pelos princípios de liberdade de expressão, de privacidade do indivíduo e de respeito aos direitos humanos, reconhecendo-os como fundamentais para a preservação de uma sociedade justa e democrática.

\section{Governança democrática e colaborativa}

A governança da Internet deve ser exercida de forma transparente, multilateral e democrática, com a participação dos vários setores da sociedade, preservando e estimulando o seu caráter de criação coletiva.

7. Inimputabilidade da rede

0 combate a ilícitos na rede deve atingir os responsáveis finais e não os meios de acesso e transporte, sempre preservando os princípios maiores de defesa da liberdade, da privacidade e do respeito aos direitos humanos.

Como se percebe com clareza, esses princípios concernem o núcleo do Estado Democrático de Direito, voltado à proteção da dignidade da pessoa humana a partir da tutela de direitos humanos como a liberdade de expressão e privacidade. Por outro lado, o meio digital em que se dá a comunicação social, o trabalho, o comércio e a política, deve ser governado de forma democrática, colaborativa e transparente, sem que haja monopólio, controle ou manipulação de informações para fins comerciais ou políticos. Percebe-se, assim, a inspiração diretamente constitucional desse Documento.

Essa vocação constitucional se reflete explicitamente no Marco Civil, cujo art. $2^{\circ}$, inciso II, prevê, como um dos fundamentos da disciplina do uso da Internet no brasil, "os direitos humanos, o desenvolvimento da personalidade e o exercício da cidadania em meios digitais". Como se verá na próxima seção, o florescimento e a dignidade da personalidade pressupõe o gozo dos bens humanos básicos da razoabilidade prática e da sociabilidade, protegidos juridicamente sob a forma de direitos humanos.

O objetivo principal desse instrumento normativo é a segurança jurídica dos usuários da rede mundial de computadores, tanto os internautas comuns, quando os provedores que franqueiam o acesso às páginas digitais, os comerciantes que se utilizam da plataforma e a própria Administração Pública. Ressalte-se que o princípio da legalidade 
é essencial para esse escopo, consoante da ordenação social de um Estado de Direito, que estabiliza as relações sociais criando um horizonte jurídico de expectativa da resolução de eventuais conflitos (SARLET; MARINONI; MITIDIERO, 2015, p. 272).

Além de princípios e direitos, o Marco Civil prevê tanto direitos, quanto mecanismos processuais para a proteção deles. Um dos eixos centrais desse instrumento regulatório é a tentativa de conciliação equânime entre o direito à liberdade de expressão e o direito à privacidade dos usuários. Interessa-nos especificamente a ênfase que a norma confere aos direitos de personalidade, sobretudo a inviolabilidade da intimidade e da vida privada e o sigilo do fluxo de informações e comunicações, excetuando-os apenas mediante ordem judicial fundamentada, consoante o devido processo legal:

Art. 10. A guarda e a disponibilização dos registros de conexão e de acesso a aplicações de internet de que trata esta Lei, bem como de dados pessoais e do conteúdo de comunicações privadas, devem atender à preservação da intimidade, da vida privada, da honra e da imagem das partes direta ou indiretamente envolvidas.

§ 1 o 0 provedor responsável pela guarda somente será obrigado a disponibilizar os registros mencionados no caput, de forma autônoma ou associados a dados pessoais ou a outras informações que possam contribuir para a identificação do usuário ou do terminal, mediante ordem judicial, na forma do disposto na Seção IV deste Capítulo, respeitado o disposto no art. $7 \mathrm{o}$.

$\S 200$ conteúdo das comunicações privadas somente poderá ser disponibilizado mediante ordem judicial, nas hipóteses e na forma que a lei estabelecer, respeitado o disposto nos incisos II e III do art. 7o. (grifos nossos)

Desse modo, os provedores estão obrigados a preservar sob o mais estrito sigilo os registros de conexão, dados pessoais e comunicações privadas, respeitando, assim, a privacidade, a intimidade, a honra e a imagem dos usuários. Ou seja, eles não podem valer-se dessas informações privilegiadas para auferir qualquer tipo de lucro ou vantagem, comercial, social ou política, para si ou para outrem. Não podem, por exemplo, vender informações sobre o comportamento digital dos usuários, as páginas que acessam, o horário do dia em que navegam, as suas conversas particulares, 
os vídeos e músicas a que assistem, e assim por diante. 0 provedor que descumprir essa norma sofre penalidades, que pode ser advertência até a proibição de exercer suas atividades (DE LUCCA, 2015).

Por outro lado, os provedores estão também obrigados a manter o registro de todos os internautas por seis meses (Art. 15), podendo disponibilizá-los apenas nos termos de ordem judicial específica, consoante os seguintes dispositivos legais:

Art. 22. A parte interessada poderá, com o propósito de formar conjunto probatório em processo judicial cível ou penal, em caráter incidental ou autônomo, requerer ao juiz que ordene ao responsável pela guarda o fornecimento de registros de conexão ou de registros de acesso a aplicações de internet.

Parágrafo único. Sem prejuízo dos demais requisitos legais, o requerimento deverá conter, sob pena de inadmissibilidade:

I - fundados indícios da ocorrência do ilícito;

II - justificativa motivada da utilidade dos registros solicitados para fins de investigação ou instrução probatória; e

III - período ao qual se referem os registros.

Art. 23. Cabe ao juiz tomar as providências necessárias à garantia do sigilo das informações recebidas e à preservação da intimidade, da vida privada, da honra e da imagem do usuário, podendo determinar segredo de justiça, inclusive quanto aos pedidos de guarda de registro. (grifos nossos)

Chegamos no ponto nevrálgico deste Trabalho, que articula o direito à privacidade ao direito ao devido processo legal no contexto do Estado Democrático de Direito. Esses artigos reforçam a inteligência do art. 5, inciso XII, da Constituição Federal, que garante a inviolabilidade do sigilo à correspondência e comunicações em geral. Embora o texto constitucional se refira a comunicações telegráficas e telefônicas, com o Marco Civil, não resta qualquer dúvida, de que essa proteção se estende ao meio digital. Essa proteção já era defendida, por interpretação analógica, pela doutrina e jurisprudência (PODESTÁ, 2015).

Como nenhum direito é absoluto, é possível a suspensão da privacidade pela quebra do sigilo mediante ordem judicial. Note-se que 
essa é uma medida extrema. 0 texto constitucional contém a ressalva "no último caso"; ou seja, a autorização judicial deve ser comprovadamente necessária e proporcional ao indício da ocorrência do ilícito. Como notam Pinto e Guimarães (2016, 204-205), "coloca-se a autoridade judiciária como guardiã da privacidade do indivíduo, num momento histórico de transição, onde o indivíduo transfere para a nuvem seus dados mais íntimos e particulares."

O fundamento jurídico dessa proteção judicial da privacidade é o direito ao devido processo legal, também insculpido na Carta Magna (inciso LIV), cuja proteção é decisiva para o funcionamento do Estado de Direito, em que a produção de provas contra os cidadãos é pautada na mais estrita legalidade. Isto é, não se pode devassar a vida íntima de alguém por mera desconfiança de um ilícito. Deve haver um nexo causal sólido para se invadir a privacidade de uma pessoa, uma vez que os direitos humanos, como os de personalidade, fundamentam a própria legitimidade do Estado de Direito, cuja autoridade serve ao bem comum. Como bem pontua Vianna (2006, p. 84):

0 direito à privacidade, concebido como uma tríade de direitos - direito de não ser monitorado, direito de não ser registrado e direito de não ser reconhecido (direito de não ter registros pessoais publicados) - transcende, pois, nas sociedades informacionais, os limites de mero direito de interesse privado para se tornar em um dos fundamentos do Estado Democrático de Direito.

Como evitar a vulgarização desse espaço sagrado de intimidade? Como não torná-lo vulnerável à exposição facilitada pelo mero clique de um programa de computador? Vianna (2006, p. 163) defende que a opacidade privada é diretamente proporcional à transparência pública. $\mathrm{Ou}$ seja, para que a intimidade do indivíduo não seja tragada pela vigilância digital, é necessário que se controle o monitoramento político do Estado, que se sabiam os critérios precisos do seu poder de investigação.

Isso concerne diretamente ao princípio característico do moderno constitucionalismo, qual seja, a separação dos poderes para fins de controle recíproco (checks and balances), como garantia dos direitos individuais contra o poder soberano e potencialmente autoritário do próprio Estado. 
A filosofia moral e política subjacente a esse instituto jurídico será exposta na próxima seção, concernente à fundamentação do Estado de Direito na teoria da lei natural de John Finnis.

Ancorado nos princípios da dignidade da pessoa humana, da separação de poderes, da legalidade e do devido processo legal, o Estado de Direito protege o direito à privacidade contra os abusos privados e estatais. 0 Estado é de Direito porque é enraizado numa Constituição que prevê os fins e o os limites da sua atuação. Interiormente dotado de meios para contenção, o Estado de Direito garante os direitos fundamentais dos cidadãos regulando o processo pelo qual esses direitos podem, excepcionalmente, ser relativizados, como no caso da persecução penal. Como exceção, essa suspensão deve ser fundamentada por decisão do juízo competente. E fundamentada no limite estrito da lei, que assegura ao cidadão os seus direitos e deveres, e as formas processuais em que pode tê-los relativizados (MENDES; COELHO; BRANCO, 2009, p. 171)

É precisamente nesse ponto que surgem as ameaças dos Projetos Legislativos em tramitação, os quais desvirtuam a constitucionalidade do Marco Civil. Incentivado por um legítimo anseio social de combate à criminalidade e à impunidade, o Projeto 215/2015 adquire contornos inconstitucionalmente punitivista quando retira do controle judicial o acesso dos dados do investigado. Ora, essa é uma garantia constitucional explícita do devido processo legal, não cabendo à legislação ordinária, nem mesmo ao constituinte derivado na forma de emendas constitucionais, abolir essa conquista (Art. 60, parágrafo $4^{\circ}$, inciso IV, da Constituição Federal).

Segundo a justificação do Projeto de Lei 1.547/2015, apensado ao Projeto de Lei 215/2015 e em tramitação no Congresso Nacional, visa-se "promover o recrudescimento do tratamento penal dispensado ao agente que pratica crimes contra a honra em sítios ou por meio de mensagens eletrônicas difundidas pela Internet". Na mesma linha, o projeto de Lei 215/2015, também apensado ao Projeto de Lei 215/2015, também convoca a atuação "mais enérgica" do Estado contra crimes contra a honra, prevendo, para tanto, a relativização do devido processo legal, ao conferir poderes imediatos às autoridades de investigação policial ou do Ministério Público para acesso a registros de Internet nos casos de crimes contra a honra cometidos mediante publicação no meio virtual, 
afastando a proteção das liberdades públicas pelo judiciário, o único que foi constitucionalmente revestido desse poder jurisdicional. Vejamos a sugestão de inclusão do Art. 23-A ao Marco Civil:

Art. 23-A. A autoridade policial ou o Ministério Público, observado o disposto neste artigo, poderão requerer, ao responsável pela guarda, registros de conexão e registros de acesso a aplicações de internet, para instruir inquérito policial ou procedimento investigatório iniciados para apurar a prática de crimes contra a honra cometidos mediante conteúdo disponibilizado na internet.

$\S 1$ o 0 requerimento apenas será formulado se presentes fundados indícios da ocorrência do crime e quando a prova não puder ser feita por outros meios disponíveis, sob pena de nulidade da prova produzida.

$\S 4^{\circ}$ Cabe à autoridade requerente tomar as providências necessárias à garantia do sigilo das informações recebidas e à preservação da intimidade, da vida privada, da honra e da imagem do usuário. (grifo nosso)

Ainda que constem as condicionantes da medida grifadas - como "fundados indícios da ocorrência de crime" e "providências necessárias à garantia do sigilo de informações recebidas e à preservação da intimidade, da vida privada, da honra e da imagem do usuário" -, esse Projeto de Lei usurpa, claramente, a prerrogativa do Poder Judiciário, outorgando-lhe à autoridade policial e ao Ministério Público, permitindo, perigosamente, o agigantamento do Estado Policial arbitrário e desmedido, um caminho pavimentado para o desenvolvimento de um Estado Totalitário, que não respeita as garantias constitucionais dos cidadãos, que passam a ser monitorados e controlados pela tecnologia da informação, sem o "filtro racional da decisão judicial” (PINTO; GUIMARÃES, 2016, p. 211-215).

Na mesma direção, a nova redação do parágrafo $1^{\circ}$ do Art. 10 , citado acima, prevê, além da "ordem judicial" a "requisição de autoridade competente" para a quebra de sigilo de dados, em clara afronta ao direito constitucional à privacidade e ao devido processo legal:

§ 1 o 0 provedor responsável pela guarda somente será obrigado a disponibilizar os registros mencionados no caput, de forma autônoma ou associados a dados pessoais ou a outras informações que possam contribuir para a identificação do usuário ou do terminal, mediante ordem 
judicial, na forma do disposto na Seção IV deste Capítulo, respeitado o disposto no art. $7 \mathrm{o}$.

Ora, dispensando a ordem judicial, qualquer protocolo formal da autoridade policial pode invadir os dados privados de um cidadão. Além da flagrante inconstitucionalidade de se querer revogar uma garantia fundamental que figura como cláusula pétrea da Constituição por meio de uma legislação ordinária, esse Projeto fere ainda a presunção de inocência. Como explicam Pinto e Guimarães (2016, p. 217):

É a presunção de inocência que garante ao indivíduo a salvaguarda do direito à privacidade, o direito de exigir uma decisão judicial fundamentada para a quebra de seu espaço privado, deixando nas mãos do Estado inquisidor a obrigação de apresentar em juízo o conjunto indiciário contrário. Para adentrar a esfera íntima, deverá o Estado Inquisidor demonstrar a necessidade e proporcionalidade da medida à autoridade judiciária competente.

Isso porque, até que uma decisão judicial marcada pela proporcionalidade e comprovada necessidade permita o acesso às suas informações privadas, todo cidadão tem garantido esse núcleo íntimo de sua personalidade, que não pode ser lastreada por mera desconfiança ou indícios infundados. A indispensabilidade de decisão judicial para quebra de sigilo de dados, portanto, é um escudo contra o Estado Arbitrário de tendência inquisitorial.

Como vimos, a sociedade da informação é marcada pelo imediatismo da comunicação e, por isso, se quer uma instrução policial e processual célere. Porém, essa urgência de enfrentar a criminalidade e a impunidade digital não pode neutralizar um direito humano fundamental tão central ao Estado Constitucional de Direito, o da privacidade, assim como o do devido processo legal que o protege.

\section{FUNDAMENTO FILOSÓFICO DO ESTADO DE DIREITO E DAS GARANTIAS FUNDAMENTAIS EM JOHN FINNIS}

Até aqui, vimos as ameaças da sociedade da informação ao direito da privacidade e a sua proteção constitucional e legal, refletindo sobre o 
risco de violação pelos Projetos Legislativos de alteração do Marco Civil. Esta seção volta-se à fundamentação filosófica do Estado de Direito, do direito à privacidade e ao devido processo legal. Sem esse embasamento teórico, a defesa desses direitos torna-se frágil e pode soar retórica. Por isso, tomamos a teoria da lei natural de John Finnis, que articula, com rigor conceitual, uma teoria da razão prática, que explica tanto a sua autoridade formal-processual quanto a sua normatividade-ética.

O grande mérito de Finnis é a articulação da problemática jurídicopolítica da autoridade com a questão moral da razão prática, na análise ética dos bens humanos básicos e do bem comum. Nessa moldura teórica, a autoridade jurídica está a serviço da coordenação social, a que o cidadão adere na sua conduta a partir da razão prática que considera o bem comum como razão para sua ação, como exigência da justiça e realização dos direitos humanos (FINNIS, 2011c).

0 Estado de Direito é a forma da autoridade, como exigência racional de estabilidade e de previsibilidade que o princípio da legalidade instaura na comunidade regida pela racionalidade do bem comum. A seu turno, o bem comum é o conjunto de condições necessárias para que cada pessoa realize os bens humanos básicos na sua vida, consoante o seu plano racional de vida.

O plano de vida pressupõe a liberdade e a autonomia de cada um, que equaciona a sua personalidade com suas intelecções racionais e preferências morais. Indivíduos e comunidades se constituem a partir de suas escolhas e decisões racionais. 0 recurso racional primário para coordenar a ação social é a autoridade do direito, que efetiva e consubstancia o bem comum. 0 direito positivo exerce autoridade, coordenando efetivamente a ação social, pela razão pública, clara, geral, estável, presente em leis publicadas, articuladas e coerentes num ordenamento jurídico estável e coeso.

O Estado de Direito é uma garantia da razão prática, por isso uma instituição imprescindível para a teoria finnisiana da lei natural. Conceitualmente, o Estado de Direito é composto por regras válidas, legitimadas por regras anteriores que remontam às fontes sociais autorizadas para a produção jurídica, a partir de critérios públicos reconhecíveis por governantes e governados e não sujeitos à indeterminação de julgamento dos conflitos que devem ser resolvidos, e não multiplicados 
ou prolongados, pela autoridade do direito. Por isso, as decisões devem ser previsíveis, estabelecendo razões excludentes e suficientes para a ação (FINNIS, 2007a, p.264).

Ou seja, as instituições e a lei, em sentido formal, são veículos da razão. 0 Estado de Direito é, portanto, uma instituição que promulga leis que se tornam razões para ação: os indivíduos precisam assimilar essas razões de ordem pública no seu plano de vida, no seu comportamento moral-racional, uma vez que o bem comum é um dos requisitos da razoabilidade prática. Eis como Finnis define o sentido focal, que constitui o caso central de direito:

Regras feitas, de acordo com regras legais reguladoras, por uma autoridade determinada e efetiva (ela própria identificada e, tipicamente, constituída como uma instituição por regras jurídicas) para uma comunidade 'completa', e escorada por sanções de acordo com as estipulações guiadas por regras de instituições judicantes, este conjunto de regras e instituições sendo direcionado a resolver de modo razoável qualquer um dos problemas de coordenação da comunidade (e ratificar, tolerar, regular ou derrogar soluções advindas de outras instituições ou fontes de normas) para o bem comum dessa comunidade, de acordo com uma maneira e uma forma adaptadas a esse bem comum por características de especificidade, minimização de arbitrariedade, e manutenção de uma qualidade de reciprocidade entre os objetos da lei entre si e também em suas relações com as autoridades legítimas (FINNIS, 2007a, p. 270).

Dessa definição, sobressai o princípio da legalidade que caracteriza o Estado de Direito, como aquele em que as regras são feitas de acordo com regras, editadas por instituições que respeitam o procedimento estabelecido pela própria lei, o que se pode denominar devido processo legal (CORREAS, 2015). Esse respeito ao princípio da legalidade evita arbitrariedade das autoridades e as legitima em uma comunidade política com pretensão de convivência pautada na razoabilidade prática, cujo conteúdo são os bens humanos básicos, a serem considerados na próxima seção.

A justificação da autoridade do direito são os limites apropriados para a atuação de seres livre e racionais, de pessoas humanas dignas que merecem respeito pelo exercício de sua liberdade racional, e não de qualquer tipo de liberdade, pois somente há liberdade se houver 
autogoverno racional. Por isso, convém explorar o fundamento substancial do Estado de direito no bem humano básico da razoabilidade prática, que tem a função arquitetônica de estruturar a ação individual e social. Trata-se da virtude da prudência, intimamente ligada à da justiça, que determina o conteúdo do que é devido a cada um.

A função do Estado de Direito, portanto, é a promoção da dignidade, liberdade e racionalidade humana na comunidade completa. A teoria finnisiana reconhece a liberdade e a autonomia moral dos indivíduos como fundamentos do Direito. Contudo, a liberdade ocupa uma função central conjugada com a dignidade humana e racionalidade, como pode ser observado na seguinte citação:

Os indivíduos só podem ser eus - isto é, ter "dignidade" de serem "agentes responsáveis" - se não forem forçados a viver suas vidas para a conveniência de outrem, mas lhes seja permitido e sejam ajudados a criar uma identidade duradoura por toda a vida. Este é o valor primário da previsibilidade que a lei busca estabelecer por meio das características formais discutidas supra (FINNIS, 2007a, p. 266).

Dessa citação, convém explicar dois pontos: 1 . a dignidade relativa à responsabilidade e liberdade de sujeitos autônomos, que não podem ser "forçados a viver suas vidas para a conveniência de outrem" e 2 . 0 valor primário da previsibilidade da lei e suas características formais. Para tanto, é necessário garantir 1. o direito à inviolabilidade da privacidade, sem o qual não se dispõe do bem humano básico da razoabilidade prática, e 2 . o direito ao devido processo legal, como meio de promoção processual da justiça e do bem comum.

No que toca ao primeiro ponto, considerando a incomensurabilidade dos bens humanos básicos, não se deve supor que o bem comum impeça a liberdade e o pluralismo. Ao contrário, o bem comum fornece os meios sociais para a realização da vida individual racional e autônoma, compatível com as outras vidas. Finnis reforça esse postulado, de forma precisa, no seguinte excerto: “

O caso central do governo político é o governo de um povo livre, e o caso central do direito é o da coordenação de sujeitos voluntários por um direito que, pelo seu caráter público (promulgado), seu claridade e generalidade, 
estabilidade e praticalidade, trata aos sujeitos como participantes da razão pública. (FINNIS, 1998, p. 257).

Em relação ao segundo ponto, as características formais da norma de que fala Finnis (2007a, p.262-264) são: 1. clareza e previsibilidade; 2. Temporalidade; 3 . capacidade de conferir poder; 4 . persistência,; 5 . ausência de lacuna e autonomia e 6. coercibilidade - sanção e prevenção. Essas características são exigências da razoabilidade prática, que precisa de clareza, estabilidade e coerência: os agentes racionais precisam saber os termos de sua ação social de antemão, para que possam planejar o seu plano de vida, inclusive sabendo o meio de resolução dos eventuais conflitos por que podem passar. No caso específico deste Artigo, tratamos do Estado de Direito relacionado à realização material do bem humano da razoabilidade prática, que compreende um direito humano e garantia fundamental (FINNIS, 2011a; 2011b).

Isso funda a necessidade do devido processo legal (due processo of law), tanto na sua dimensão formal (como as nossas garantias constitucionais processuais da ampla defesa, contraditório, duplo grau de jurisdição e presunção de inocência), quanto na sua dimensão material e substancial (dos direitos humanos fundamentais que garante).

Com essa dupla pauta, Finnis alcança as duas funções precípuas de uma teoria jurídico-política, a substantiva, composta pelos padrões ético-materiais normativos de correção das ações, e a institucional, formada pelos critérios que possibilitam a racionalidade da comunicação intersubjetiva ordenada por regras (leis e procedimentos) que estabilizam as relações sociais, antecipando a resolução dos conflitos de cooperação.

A teoria da lei natural identifica condições e princípios de razoabilidade prática, de bondade e ordem entre as pessoas, na sociedade e na conduta social. Os bens humanos básicos são valores intrínsecos, aspectos gerais do bem-estar pessoal que constituem o florescimento (felicidade), que dependem das condições sociais, jurídico-políticas do bem comum. Por isso, todos são, de algum modo, moral e juridicamente responsáveis pelo bem comum, porque não é possível o florescimento humano individualizado, isolado da rede que compõe a comunidade completa que é o Estado (BATNITZKY, 1995). 
Segundo Finnis (2007a, p. 91-95), há sete os bens humanos básicos: vida, conhecimento, jogo, experiência estética, sociabilidade, razoabilidade prática e religião. Como condição do florescimento pessoal de cada pessoa, eles fundam direitos humanos e garantias fundamentais, que são as exigências da justiça constitutivas do bem comum. Neste Artigo, interessam-nos os bens da sociabilidade prática, que funda as exigências interpessoais da justiça, e da razoabilidade prática.

0 bem da sociabilidade é a capacidade de relação interpessoal pela qual nos comunicamos e formamos comunidades (FINNIS, 2007a, p. 143). Esse bem se realiza, maximamente, na amizade voltada ao bem comum, como visto acima, quando tratamos do conceito de autoridade e Estado de Direito formal. Em razão da definição de direito ser orientado para o bem comum, é preciso entender o que significa a comunidade completa que é coordenada para esse fim (GREEN, 2013).

0 tipo de comunidade completa que o Estado é se baseia no bem comum instrumental. Na família ou nas relações pessoais de amizade há um bem comum substancial compartilhado, mas na relação dos cidadãos num Estado não existe uma relação direta e substancial entre todos que compões o Estado, mas há uma responsabilidade indireta de todos os cidadãos de não impedirem, ou mesmo facilitarem, o bem dos outros membros da comunidade (FINNIS, 1998, p. 222). Por sua vez, o bem comum político é instrumental, configurando o horizonte de realização individual dos bens humanos básicos limitado ou promovido pelos demais, auxiliado pelo Estado para que cada um realize seu plano de vida (DUKE, 2013).

Um plano de vida só será razoável se desenvolvido com autonomia, autenticidade e integridade, e se for articulado ao bem da sociabilidade (comunicação e formação de comunidades). Assim, percebe-se a relação do direito à privacidade com o bem básico da razoabilidade prática, na sua dimensão normativa.

Quem se arvora a comunicar a sua intimidade com quem queira, exercendo o bem da razoabilidade, se não tiver o direito à privacidade resguardado por um Estado de Direito que o proteja de invasões digitais?

0 bem da razoabilidade prática tem função arquitetônica no equacionamento dos planos de vida, tanto o individual-ético, quanto o social-jurídico. No nível da prudência pessoal, reflito e decido o que fazer 
a partir do horizonte de possibilidades que a ordem jurídica do Estado de Direito (bem comum) me oferece. Assim, tendo acesso a direitos e garantias fundamentais como vida, saúde, segurança, educação, trabalho, comunicação, religião, esporte, cultura e lazer, tomo decisões morais concretas que constituem a minha personalidade. Por exemplo, decido questões morais como casamento, religião, profissão, esporte, formando um plano coerente de vida, que expressa a minha racionalidade prática (moral), conferindo-me identidade duradoura perante minha consciência e perante a sociedade (FINNIS, 2007a, p. 108).

Ora, a formação da personalidade pessoal está relacionada à apresentação pública que cada pessoa, como agente racional, fornece à sociedade, o que pode ser considerado a sua honra, o valor ou estima que tem a partir do que é e do que faz. Para além da dignidade universal de cada pessoa humana como agente livre e racional (FINNIS, 1998, p. 176), cada um tem a sua honra pública, como o reconhecimento social pelo papel que ocupa na comunidade. A apresentação da minha pessoa, incluindo a minha presença física, imagem, voz e propriedade, depende da minha liberdade, da minha decisão pessoal.

É por isso que o direito à intimidade e privacidade constituem o núcleo dos direitos da personalidade, inclusive na dimensão processual. Os Projetos Legislativos estudados na seção anterior podem relativizar o devido processo legal e a presunção de inocência, interferindo diretamente na segurança jurídica das relações sociais pela Internet, uma vez que todos estão expostos à persecução policial, independente de autorização judicial.

Por causa da nossa razoabilidade e da dignidade dos outros, não podemos instrumentalizá-los aos nossos interesses privados, atentando contra o bem comum. Esse bem é tão fundamental para a realização da justiça que é protegido na forma de direitos e garantias fundamentais, cujo descumprimento gera responsabilização civil dos ofensores.

Um dos maiores expoentes da nova teoria da lei natural, Robert George (1993, p. 210-217), por sua vez, relaciona o direito à privacidade à moralidade pública do bem comum, composta pelos bens humanos básicos, numa teoria perfeccionista e pluralidade das liberdades civis. Para ele, a privacidade relaciona-se diretamente à autonomia, que pode ser considerada a capacidade de autoformação racional do agente moral. 
George (1993, p. 191-192) considera que a privacidade é uma liberdade civil, e que, como tal, não é valiosa em si mesma, mas como instrumento aos bens que realiza de modo razoável e harmônico com a realização dos outros agentes racionais e autônomos (bem comum). Ou seja, o foro íntimo e o livre agir são meios ou condições para se atingir bens intrínsecos, como relações sociais saudáveis, pautados no reconhecimento recíproco das identidades, a partir da alteridade.

Como já reforçado, o bem da razoabilidade prática relaciona-se à sociabilidade. Para que eu me comunique a contento com os demais, é necessário que minha personalidade seja bem compreendida e assimilada por eles. Em outras palavras, eu devo parecer perante os outros como de fato eu sou, autêntico e íntegro. Por isso, não posso ter a minha personalidade desfigurada pela comunicação digital da Internet, por exemplo, sob o risco de não me relacionar razoavelmente com os outros. A perda da autenticidade e da integridade atenta diretamente contra a dignidade humana, fundada na racionalidade do agente moral autônomo e autodeterminado.

A concepção tradicional do valor e do direito à privacidade atenta: 1 . para os lugares protegidos; e 2. para o controle de informações pessoais sobre si mesmo. Isto é, segundo George (1993, p. 211), trata-se do "direito essencialmente processual de ser livre de intrusões governamentais e outras, em casa, no escritório ou em outras instalações, ou em arquivos, documentos ou outros registros", salvo se o governo puder justificar a invasão do espaço privado ou analisar informações privadas por meio de razões consistentes de bem comum. Todos os direitos humanos são limitados pelas exigências do bem comum, da ordem pública (FINNIS, 2007a, p.206).

A privacidade concerne à interioridade, da qual provém a comunicação autêntica. As pessoas percebem em si mesmas o valor intrínseco da comunicação e da formação de comunidades quando cooperam livremente para fins comuns. Desse modo, uma comunidade pressupõe que duas ou mais pessoas independentes tenham capacidade de comunicar à(s) outra(s) a sua interioridade, a fim de alcançar certa unidade de entendimento e vontade. Sem o respeito à privacidade, não há o processo de exteriorização autêntica e fiel da interioridade para as 
pessoas desejadas, com quem se quer formar uma comunidade, portanto não há comunicação efetiva, razoável.

0 direito à privacidade, portanto, preocupa-se com o autodesenvolvimento individual valioso, pautado na razoabilidade prática dos agentes morais. Daí a necessidade de proteção a esse direito, na forma de garantia fundamental, pelo Estado de Direito na sua dimensão substancial. 0 valor da privacidade (assim como o da liberdade de expressão) está na garantia da integridade das pessoas e das comunidades, sem há qual não se pode gozar do bem da harmonia interpessoal (GEORGE, 1993, p. 214).

Por isso, pode-se afirmar que a cooperação social autêntica, em si um bem humano básico, seria impossível se houvesse uma fusão de pessoas que aniquilasse a interioridade uma das outras (GEORGE, 1993, p. 211), ou seja, a individualidade precisa ser mantida como condição da cooperação livre e da comunidade autêntica. Isso porque a comunicação da minha interioridade, por minha livre vontade, para outrem é essencial para haver cooperação.

Caso contrário, subvertem-se a comunicação e a cooperação, as quais pressupõem uma unidade de compreensão e de intenção. Quando não se respeita a privacidade, na qual se protege a intimidade moral da pessoa, tem-se a dominação e a manipulação que privam a cooperação genuína, baseada na comunicação intencional de sentidos compartilhados por indivíduos livres.

Note-se o quanto esta teoria encontra ressonância com as garantias atuais do Marco Civil da Internet. No seu Art. 10, já apresentado acima, o Marco Civil prevê que a guarda e a disponibilização dos registros digitais "devem atender à preservação da intimidade, da vida privada, da honra e da imagem das partes direta ou indiretamente envolvidas". Ademais, este conteúdo privado só pode ser disponibilizado "mediante ordem judicial", exatamente para garantir a segurança jurídica dos usuários, que formam as suas personalidades das relações sociais privadas e íntimas, cientes de quem terceiros não as devassam.

Marcada pela ambiguidade de todo instrumento técnico, que pode ser utilizado para o seu fim (bem) intrínseco ou para fins escusos, prejudiciais a bens humanos básicos, a Internet potencializa extraordinariamente a 
comunicação interpessoal, mas também facilita e promove novas formas de dominação e manipulação da intimidade alheia. Daí a importância capital de um Estado de Direito que tenha autoridade para garantir os direitos fundamentais da pessoa humana livre e racional.

Na seção anterior, vimos que o Marco Civil, no seu art. $2^{\circ}$, fundamentase nos direitos humanos, no desenvolvimento da personalidade e no exercício da cidadania em meios digitais. Ademais, seu objetivo precípuo é o de normatizar as relações digitais a fim de lhes assegurar segurança jurídica, com base no princípio fundamental do Estado de Direito, qual seja o da legalidade e do devido processo legal. Nesse contexto, percebe-se a importância que a norma confere aos direitos de personalidade, como a inviolabilidade da intimidade e da vida privada.

Vimos, com base em Vianna (2006, p. 163) que a proteção da intimidade do indivíduo depende do monitoramento do Estado, o qual, entretanto, deve ser pautado em critérios legais e processuais. A teoria da lei natural de Finnis que analisamos nesta seção articula exatamente a dimensão formal com a material do Estado de Direito, que nos parece ameaçado com o Projeto 215/2015, que reveste o Marco Civil de uma feição punitivista quando retira do controle judicial o acesso dos dados do investigado.

Consideramos que não se pode relativizar tal garantia constitucional, porque o devido processo legal é uma cláusula pétrea, um direito fundamental que não pode ser suspenso nem mesmo pelo constituinte derivado, na forma de emendas constitucionais (Art. 60, parágrafo $4^{\circ}$, inciso IV, da Constituição Federal), muito menos pela legislação ordinária.

Consoante a teoria de John Finnis (2007b, p. 96), a lei positiva deriva da lei natural por conclusão (necessária) ou por determinação (contingente). A conclusão é quando a lei positiva extrai a sua normatividade diretamente da razão prática, sem poder relativizá-la, uma vez que dela depende a consecução do bem comum. No caso estudado, a dignidade da pessoa humana e o florescimento dos agentes racionais dependem diretamente da segurança jurídica e da legalidade do devido processo legal, sem o qual a sua privacidade estão ameaçadas.

Por isso, esses institutos não são positivados por determinação, em que há um espaço de discricionariedade do legislador positivo para exercer 
a razoabilidade prática a depender das contingências, como seria o caso de delimitar um prazo processual, o tamanho do teto de um hospital, ou, num exemplo mais próximo ao estudado, decidir por tipos de provedor ou velocidade de internet permitidos, conforme especificidades técnicas de conveniência social e mercadológica.

Nesses casos, trata-se de uma "particularização que une a necessidade racional do princípio com a liberdade (do legislador) de escolher entre concretizações alternativas, uma liberdade que inclua mesmo elementos (em um sentido benigno) de arbitrariedade." (Finnis, 2007b, p. 96-97).

A relativização do devido processo legal nos Projetos de Lei analisados não alteram institutos jurídicos relativos, como medidas "puramente positivas" a serem adequadas, prudencialmente, conforme a contingência das circunstâncias. Pelo contrário, trata-se de uma garantia constitucional extraída diretamente do princípio da dignidade humana, que fornece os direitos humanos fundamentais para a realização do bem comum. Sem a privacidade material e processualmente garantidas, a pessoa humana tem a sua razoabilidade e liberdade ameaçadas, afetando diretamente $o$ bem comum, o qual justifica o Estado de Direito.

Nesse caso, a derivação da lei natural (princípios de razoabilidade prática) à lei positiva se dá por conclusão, marcada por uma relação lógica de necessidade. Não se pode garantir a liberdade de agentes racionais autodeterminados sem as garantias constitucionais do devido processo legal. Mudar essa regulamentação, como pretendem os projetos legislativos estudados, não cabe à discrionariedade do legislador positivo, que se encontra vinculado, nesse aspecto, à lei natural. É a derivação por conclusão que garante a liberdade social dos agentes racionais.

Se o Projeto de Lei 215/2015 alterar o Marco Civil, dispensando a ordem judicial, qualquer a autoridade policial poderia invadir diretamente os dados privados de um cidadão, evidenciando uma tendência inquisitorial que afeta a presunção de inocência, no contexto de uma política jurídica autoritária, incompatível com o Estado de Direito.

Vê-se, assim, que o problema jurídico nesse Artigo a partir da perspectiva filosófica de John Finnis encontra uma fundamentação mais sólida e coerente com a Constituição Federal, pois o Estado de Direito é a garantia da razão prática no âmbito público, em que os planos 
racionais de vida podem se equacionar de forma equilibrada e justa, consoante o bem comum.

\section{CONCLUSÃO}

Este Artigo analisou a crescente complexidade da sociedade da informação em que vivemos. Nela, a fronteira entre o público e o privado se apaga gradualmente. Toda nossa existência parece lastreada em sistemas de computadores interconectados, sem que possamos monitorar o que comunicamos ou fazemos no ambiente virtual. Nesse contexto, o direito à privacidade encontra-se gravemente ameaçado.

O Marco Civil da Internet (Lei 12.965/2014) é o instrumento regulatório fundamental da matéria em nosso país. Por um lado, consoante o princípio da legalidade, ele garantiu a segurança jurídica das relações digitais, assegurando direitos fundamentais de liberdade e de privacidade, assim como do devido processo legal.

Por outro lado, essa norma ainda é alvo de muitas críticas e incertezas, tanto no poder judiciário quanto no poder legislativo. Identificamos nos Projetos de Lei 215/2015, 1.547/2015 e 1.589/2015, em tramitação no Congresso Nacional, tentativas de desvirtuá-lo gravemente, atentando contra os direitos fundamentais da privacidade e do devido processo legal, ao permitir a suspensão do sigilo bancário, por autoridade policial ou do Ministério Público, esquivando a autoridade judicial. Por isso, refletimos sobre os fundamentos jurídicos do Estado de Direito, da separação dos poderes, do princípio da legalidade e da segurança jurídica, concluindo que esses Projetos carecem de legitimidade diante dos imperativos da dignidade da pessoa humana.

A fim de robustecer a nossa tese, aprofundamos a reflexão na seara filosófica, analisamos o conceito de Estado de Direito na sua dimensão formal de autoridade, como meio de resolução de problemas de cooperação, pautada no princípio do devido processo legal, conferindo razoabilidade às diretivas políticas e jurisdicionais do Estado. Em seguida, articulamos o conceito de Estado de Direito a partir da sua finalidade de consecução 
do bem comum, composto por bens humanos básicos, que constituem bens jurídicos protegidos por direitos fundamentais.

Para entender o conceito de Estado de Direito na teoria da lei natural de John Finnis foi necessário enfocá-lo no quadro mais amplo da sua teoria ética da razão prática, que estuda os fundamentos da ação humana em sociedade. A hipótese central é a de que o Estado de Direito, na sua dimensão formal (processual) e substancial (ética), reivindica autoridade legítima sobre os cidadãos e jurisdicionados por servir ao bem comum.

O conceito finnisiano de Estado de Direito responde, assim, a essa dupla necessidade de justificação, tanto a formal, quando a substancial. Do ponto de vista formal (procedimental, processual), o Estado de Direito, ancorado no princípio da legalidade, garante a racionalidade e transparência de suas diretivas, podendo direcionar a razão prática dos jurisdicionados. Do ponto de vista substancial (ético e finalístico), o Estado de Direito, baseado no princípio da justiça, promove o bem comum, o horizonte de realização livre e individual dos bens humanos básicos dos cidadãos.

Com isso, enfrentamos o desafio da interdisciplinaridade que a Internet propõe, fechando um arco argumentativo que partiu da contextualização da sociedade da informação, refletiu sobre os direitos fundamentais da privacidade e devido processo legal, no Marco Civil da Internet e na Constituição, e refletiu sobre os fundamentos filosóficos do Estado de Direito, a partir de uma teoria da razão prática que articule Ética e Direito pelo conceito de bem comum.

Concluímos que não se podem separar o direito à privacidade do direito ao devido processo legal, sob o risco de enfraquecer, mesmo neutralizar o Estado de Direito, garantia da segurança e estabilidade jurídica. Portanto, nesse ponto, demonstramos que os Projetos de Lei são inconstitucionais e que violam o direito à privacidade. 


\section{REFERÊNCIAS}

BATNITZKY, L. A Seamless Web? John Finnis and Joseph Raz on Practical Reason and the Obligation to Obey the Law. Oxford Journal of Legal Studies, N 2. Oxford Press, 1995.

BAUMAN, Z. Danos colaterais. Desigualdades sociais numa era global. Tradução de Carlos Alberto Medeiros. Rio de Janeiro: Zahar, 2013.

BRASIL. Lei n. 12.965, de 23 de abril de 2014. Estabelece princípios, garantias, direitos e deveres para o uso da Internet. Marco Civil da Internet. Brasília, DF, 23 abr. 2014.

BRASIL . Resolução CGI.br/RES/2009/003/P. Princípios para a governança e uso da internet no Brasil, São Paulo, SP, 2009.

CORREAS, Carlos I. Massini. 'La concepción normativa del gobierno del Derecho: nuevas objeciones al rule of law y una respuesta desde las ideas de John Finnis'. Persona y Derecho, vol. 73, pp. 203-230, 2015.

DE LUCCA, N. Marco Civil da Internet: uma visão panorâmica dos principais aspectos relativos às suas disposições preliminares. In: DE LUCCA, Newton; SIMÃO FILHO, A; LIMA, C.R.P.de (org.). Direito e Internet III: Marco Civil da Internet (Lei n. 12.965/2014). São Paulo: Quartier Latin, 2015.

DUKE, George. 'Finnis on the Authority of Law and the Common Good'. Legal Theory, vol. 19, pp. 44-62, 2013.

FINNIS, John. Reason in action. Oxford: Oxford University Press, 2011a.

FINNIS, John. Human Rights and Common Good. Oxford: Oxford University Press, 2011b.

FINNIS, John. Philosophy of Law. Oxford: Oxford University Press, 2011c.

FINNIS, John. Aquinas: moral, political and legal theory. New York: Oxford Press, 1998.

FINNIS, John. Lei natural e direitos naturais. São Leopoldo, 2007a.

FINNIS, John. Direito natural em Tomás de Aquino. Sua reinserção no contexto do juspositivismo analítico. Porto Alegre: Sergio Antonio Fabris Editor, 2007b. 
GEORGE, R. P. Making men moral. Civil liberties and public morality. Oxford Press, 1993.

GREEN, Leslie. 'The Nature of Limited Government'. In: GEORGE, R. P.; KEOWN, J. (eds.). Reason, Morality, and Law: The Philosophy of John Finnis. Oxford: Oxford University Press, 2013. p. 186-203.

HOVEN, J. V.D. Information technology, privacy, and the protection of personal data. In: HOVEN, J. V.D. ; WECKERT, J. (eds.) Information technology and moral philosophy. Cambridge: Cambridge University Press, 2008, p. 301-322.

MENDES, G.F.; COELHO, I.M.; BRANCO, P.G.G.. Curso de Direito Constitucional. 4⿳亠丷a ed. rev. atu. São Paulo: Saraiva, 2009.

OLIVEIRA, R.S.; BARROS, B.M.C.de; PEREIRA, M.N. O direito à privacidade na internet: desafios para a proteção da vida privada e o direito ao esquecimento. Revista da Faculdade de Direito da UFMG, Belo Horizonte, n. 70, pp. 561 594, jan./jun. 2017.

PINTO, F.M.; GUIMARÃES J.W.B. O direito à privacidade e o sigilo de dados na Internet. Revista da Faculdade de Direito da UFMG, Belo Horizonte, n. 69, p. 201-219, jul./dez. 2016.

PODESTÁ, F.H.. Direito à intimidade em ambiente da internet. In: DE LUCCA, Newton; SIMÃO FILHO, Adalberto (org.). Direito e Internet - aspectos jurídicos relevantes. $2^{\mathrm{a}}$ ed. São Paulo: Quartier Latin, 2005.

ROCHA, M.V.; CUNHA, I.R.; OLIVEIRA, K.F.R. Esquecimento, internet e "preferência" da informação. Revista Brasileira de Políticas Públicas, Brasília, v. 7, no 3,2017 p. $483-509$

SARLET, I.W.; MARINONI, L.G.; MITIDIERO, D. Curso de Direito Constitucional. $4^{\underline{a}}$ ed. amp. São Paulo: Saraiva, 2015.

TEIXEIRA, T.; SABO, P.H.; SABO, I.C. Whatsapp e a criptografia ponto-a-ponto: tendência jurídica e o conflito privacidade vs. interesse público. Revista da Faculdade de Direito da UFMG, Belo Horizonte, n. 71, pp. 607 - 638, jul./ dez. 2017.

VIANNA, T.L. Transparência pública, opacidade privada: $o$ Direito como instrumento de limitação do poder na sociedade de controle. $181 \mathrm{f}$. Tese (Doutorado em Direito) - Faculdade de Direito, Universidade Federal do Paraná, Curitiba. 2006. 
VIEIRA, T.M. 0 direito à privacidade na sociedade da informação: efetividade desse direito fundamental diante dos avanços da tecnologia da informação. Dissertação (Mestrado em Direito). Universidade de Brasília, Brasília, 2007.

Recebido em: 13-11-2018

Aprovado em: 06-11-2020

\section{Victor Sales Pinheiro}

Doutor em Filosofia pela UERJ (Tese sobre Heidegger e Platão). Mestre em Filosofia pela PUC-RIO (Dissertação sobre a República de Platão). Graduado em Direito no Centro Universitário do Pará. Entre 2006 e 2010, coordenou as atividades do filósofo e crítico literário Benedito Nunes no Centro de Cultura e Formação Cristã (CCFC) em Belém, Pará. De Benedito Nunes, organizou e apresentou os seguintes livros: A clave do poético; (Cia das Letras - Prêmio Jabuti de Teoria e Crítica Literária 2011), Ensaios Filosóficos; (Martins Fontes), Do Marajó ao arquivo: breve panorama da cultura no Pará\&quot; (Ed.Ufpa/SecultPa), A Rosa o que é de Rosa - Literatura e Filosofia; (Difel),;Heidegger; (Loyola).É organizador, junto com Luiz Costa Lima, do livro; Benedito Nunes - o pensamento poético; (Azougue Editorial) e, junto com Célia Jacob, da Revista Asas da Palavra n.25, edição em homenagem a Benedito Nunes (Ed.UNAMA - Universidade da Amazônia. Professor Adjunto da Universidade Federal do Pará (UFPA) e do Centro Universitário do Pará (CESUPA), na graduação e pós-graduação. Coordenador dos Grupos de Pesquisa (CNPq). E-mail: vvspinheiro@yahoo.com.br

\section{Alexandre Pereira Bonna}

Doutor em Direito pela Universidade Federal do Pará - UFPA (2018), com sanduíche na University of Edinburgh. Mestre em Direito pela Universidade Federal do Pará - UFPA (2015). Graduado em Direito pela Universidade Federal do Pará - UFPA (2012). Atualmente é Professor de graduação e pós-graduação do CESUPA e FACI-WYDEN. Professor Orientador da Liga Acadêmica Jurídica do Pará - LAJUPA e da Liga Acadêmica Jurídica de Responsabilidade - LAJURE. Parecerista das Revistas Civilística, Quaestio Iuris e REDES. Associado Fundador e Diretor Adjunto do Instituto Brasileiro de Estudos de Responsabilidade Civil - IBERC. Advogado-Sócio do Escritório Coelho de Souza.

E-mail: alexandrebonna@yahoo.com.br

Universidade Federal do Pará, Instituto de Ciências Jurídicas.

Rua Augusto Corrêa, 1 (Núcleo Universitário) Guamá,

66075900 - Belém, PA - Brasil 
